\title{
Genomic prediction of serum biomarkers of health in early lactation
}

\author{
T. D. W. Luke,,$^{1,2} \oplus$ T. T. T. Nguyen, ${ }^{1} \oplus$ S. Rochfort, ${ }^{1,2} \odot$ W. J. Wales, ${ }^{3}$ C. M. Richardson, ${ }^{1,2}$ M. Abdelsayed, ${ }^{4}$ \\ and J. E. Pryce ${ }^{1,2 *}$ (i) \\ ${ }^{1}$ Agriculture Victoria Research, AgriBio, Centre for AgriBioscience, Bundoora, Victoria 3083, Australia \\ ${ }^{2}$ School of Applied Systems Biology, La Trobe University, Bundoora, Victoria 3083, Australia \\ ${ }^{3}$ Agriculture Victoria Research, Ellinbank Centre, 1301 Hazeldean Rd., Ellinbank, Victoria 3820, Australia \\ ${ }^{4}$ Datagene Ltd., AgriBio, Centre for AgriBioscience, Bundoora, Victoria 3083, Australia
}

\section{ABSTRACT}

In this study, we estimated genetic parameters and genomic prediction accuracies of serum biomarkers of health in early-lactation dairy cows. A single serum sample was taken from 1,393 cows, located on 14 farms in southeastern Australia, within $30 \mathrm{~d}$ after calving. Sera were analyzed for biomarkers of energy balance ( $\beta$-hydroxybutyrate and fatty acids), macromineral status ( $\mathrm{Ca}$ and $\mathrm{Mg}$ ), protein nutritional status (urea and albumin), and immune status (globulins, albuminto-globulin ratio, and haptoglobin). After editing, 47,162 SNP marker genotypes were used to estimate genomic heritabilities and breeding values (GEBV) for these traits in ASReml. Heritabilities were low for $\beta$-hydroxybutyrate, fatty acids, $\mathrm{Ca}, \mathrm{Mg}$, and urea $(0.09 \pm 0.04,0.18 \pm 0.05,0.07 \pm 0.04,0.19 \pm 0.06$, and $0.18 \pm 0.05$, respectively), and moderate for albumin, globulins, and albumin-to-globulin ratio $(0.27 \pm$ $0.06,0.46 \pm 0.06$, and $0.41 \pm 0.06$, respectively). The heritability of haptoglobin concentration was close to 0 . The magnitude of genetic correlations between traits (estimated using bivariate models) varied considerably (0.01 to 0.96), and standard errors of these correlations were high (0.02 to 0.44). Interestingly, the direction of most genetic correlations was favorable, suggesting that selecting for more optimal concentrations of one biomarker may result in more optimal concentrations of other biomarkers. Correlations between biomarker GEBV and existing breeding values for survival, somatic cell count, and daughter fertility were small to moderate (0.07 to 0.45$)$ and favorable, whereas correlations with breeding values for milk production traits were small $(\leq 0.15)$. Accuracies of GEBV were evaluated by using 5 -fold cross validation, and by calculating accuracies from prediction error variances associated

Received June 18, 2019.

Accepted August 21, 2019.

*Corresponding author: jennie.pryce@agriculture.vic.gov.au with the GEBV. Accuracies of GEBV predicted using 5 -fold cross validation were low (0.05 to 0.27 ), whereas the means of individual accuracies were greater, ranging from 0.31 to 0.51 . Although increasing the size of the reference population should theoretically improve accuracies, our results suggest that genomic prediction of health biomarkers may allow identification of cows that are less susceptible to diseases in early lactation. Key words: biomarker, health, metabolic stability, immune response, energy balance

\section{INTRODUCTION}

Improved animal health and resilience are increasingly important breeding objectives for the dairy industry (Boichard and Brochard, 2012). Most disease events affecting dairy cows occur in the first 30 d after calving (LeBlanc et al., 2006). Many of these diseases are associated with metabolic disorders such as ketosis and hypocalcemia (DeGaris and Lean, 2008; Ospina et al., 2010; McArt et al., 2013), which can have deleterious effects on animal health and welfare and farm profitability (Suthar et al., 2013; McArt et al., 2015). Although heritability estimates of metabolic disorders are generally low (Uribe et al., 1995; Pryce et al., 2016), sufficient genetic variation exists to indicate that improvement in metabolic health can be achieved through genetic selection. Furthermore, several authors have reported favorable genetic correlations between different metabolic disorders (Heringstad et al., 2005; Jamrozik et al., 2016) and between metabolic disorders and diseases such as mastitis and reproductive disorders (Lyons et al., 1991; Oikonomou et al., 2008a). These relationships suggest that selecting for improvements in metabolic health may lead to improvements in overall animal health.

Phenotypes used to investigate the genetic parameters of health traits include producer- or veterinarianrecorded health data (Neuenschwander et al., 2012; Parker Gaddis et al., 2014; Egger-Danner et al., 2015) and biomarkers of health measured in blood or milk 
(Koeck et al., 2014; Tsiamadis et al., 2016a; Cecchinato et al., 2018). Health data have the advantage of being widely available, but their usefulness is often limited by underreporting or inconsistent recording, and by the fact that trait definitions are often restricted to binary clinical disease events (Østerås et al., 2007). In contrast, biomarker concentrations provide more accurate and objective phenotypes and have continuous distributions that enable the identification of both clinical and subclinical health disorders. Subclinical health disorders are important because of their relatively high prevalence and significant negative effects on animal welfare and performance (Macrae et al., 2006; McArt et al., 2012; Suthar et al., 2013). Commonly used biomarkers include those associated with energy balance (BHB and fatty acids), macromineral status ( $\mathrm{Ca}$ and $\mathrm{Mg}$ ), protein nutritional status (urea and albumin), and immune status (globulins and albumin-to-globulin ratio, A:G) (Whitaker, 2004; Anderson, 2009). Although extremely valuable, collecting such phenotypes is time consuming and costly, and the collection process is invasive to the animal, making their use impractical in traditional large-scale genetic evaluations, yet good candidates for genomic prediction.

Genomic selection offers exciting potential application for achieving genetic improvement in economically important but difficult-to-measure and lowly heritable health traits, by using data obtained from relatively small genotyped reference populations with highquality phenotypic data (Boichard and Brochard, 2012; Egger-Danner et al., 2015; Abdelsayed et al., 2017). Examples include genomic selection for residual feed intake (Pryce et al., 2012), tolerance to heat (Nguyen et al., 2016), resistance to bovine tuberculosis (Tsairidou et al., 2014), and enhanced immune response (Thompson-Crispi et al., 2012a).

The aims of this study were to estimate (1) the genetic parameters of serum biomarkers of health in early-lactation dairy cows using data collected from a genotyped female reference population, and (2) the accuracy of genomic predictions of serum biomarker concentrations. If sufficiently accurate, genomic selection for improved metabolic health offers the potential to provide permanent and cumulative improvements in dairy cow health and resilience, thereby increasing animal welfare and farm profitability.

\section{MATERIALS AND METHODS}

All procedures undertaken in this study were conducted in accordance with the Australian Code of Practice for the Care and Use of Animals for Scientific Purposes (NHMRC, 2013). Approval to proceed was granted by the Agricultural Research and Extension
Animal Ethics Committee of the Department of Jobs, Precincts and Resources Animal Ethics Committee (Attwood, Victoria, Australia), and the Tasmanian Department of Primary Industries, Parks, Water and Environment (Animal Biosecurity and Welfare Branch, New Town, Tasmania, Australia).

\section{Phenotypes: Serum Biomarkers}

A single serum sample (approximately $4 \mathrm{~mL}$ ) was taken from 1,393 early-lactation Holstein-Friesian cows from 14 farms in southeastern Australia between $\mathrm{Au}-$ gust 2017 and October 2018, according to the protocol described in Luke et al. (2019). All cows were between 0 and 30 DIM at the time of sampling. This DIM range was chosen because (1) it is the period in which $75 \%$ of disease events affecting dairy cattle occur (LeBlanc et al., 2006), and (2) all farms involved in this study operated a seasonal calving pattern, with large numbers of animals calving in a short period. This made making multiple visits impractical, and the aim of our experimental design was to maximize both the number of animals in the immediate postcalving period and the total number of animals that could be sampled in a single visit.

Sera were analyzed for biomarkers of energy balance (BHB and fatty acids), mineral status ( $\mathrm{Ca}$ and $\mathrm{Mg}$ ), protein nutritional status (urea and albumin), and immune status (globulins, A:G, and haptoglobin) by Regional Laboratory Services (Benalla, Victoria, Australia). The concentrations of biomarkers were determined using the following assays: enzymatic kinetic assays for BHB (McMurray et al., 1984) and urea (Wilcox et al., 1966); enzymatic end-point assay for fatty acids (proprietary formulation, Randox Laboratories, Crumlin, UK); arsenazo III for Ca (Janssen and Helbing, 1991); xylidyl blue for Mg (Svoboda and Chromý, 1971); bromocresol green for albumin (Dumas et al., 1997); biuret for total protein (Gornall et al., 1949); and peroxidase activity for haptoglobin (Makimura and Suzuki, 1982). All assays were performed using a Kone 20 XT clinical chemistry analyzer (Thermo Fisher Scientific, Waltham, MA) with reagents supplied by Randox Laboratories for fatty acids, $\mathrm{Ca}, \mathrm{Mg}$, and urea, and by Regional Laboratory Services for BHB, albumin, total protein, and haptoglobin (Makimura and Suzuki, 1982). Globulin concentrations were calculated as total protein concentration minus albumin concentration, and $\mathrm{A}: \mathrm{G}$ as albumin concentration divided by globulin concentration. Descriptive statistics of phenotypes, including the number of samples analyzed and optimal concentrations ranges for each biomarker, are shown in Table 1. Preliminary data analysis was undertaken using $\mathrm{R}$ version 3.6.0 (R Core Team, 2019). 


\section{Genomic Analysis}

Genotypes and Population Structure. Genotypes for the 1,393 animals used in this study were provided by DataGene Ltd. (AgriBio, Bundoora, Victoria, Australia). After editing using the method described in Erbe et al. (2012), 47,162 SNP markers were available for genomic analyses. A genomic relationship matrix (GRM) was constructed according to Yang et al. (2010). Principal component analysis of the GRM was performed to examine the population structure of the data set. Plots of the first 5 principal components, which summed to a total of $37 \%$ of the variation within the GRM, were visually examined and no subpopulations were identified, confirming that the population was predominantly Holstein.

Genetic Parameters. First, variance components were estimated for each biomarker trait using single linear mixed animal models in ASReml version 4.1 (Gilmour et al., 2015). In matrix notation, the model used was

$$
\mathbf{y}=\mathbf{X b}+\mathbf{Z u}+\mathbf{e},
$$

where $\mathbf{y}$ is a vector of biomarker concentrations (BHB, fatty acids, $\mathrm{Ca}, \mathrm{Mg}$, urea, albumin, globulins, A:G, haptoglobin); $\mathbf{b}$ is a vector of fixed effects of DIM at time of sampling (covariate, from 0 to $30 \mathrm{~d}$, either as a linear, linear + quadratic, third-order orthogonal polynomial, or fourth-order orthogonal polynomial), herd (14 levels, with a range of 10 to 254 cows per herd), parity (4 levels, defined as 1, 2, 3, or 4+), and date of sample collection (class variable with 20 levels); $\mathbf{u}$ is a vector of random genetic effects; $\mathbf{e}$ is a vector of the random residual effects; and $\mathbf{X}$ and $\mathbf{Z}$ are incidence matrices for $\mathbf{b}$ and $\mathbf{u}$, respectively. It is assumed that $\operatorname{var}(\mathbf{u})=\mathbf{G R M} \sigma_{u}^{2}, \operatorname{var}(\mathbf{e})=\mathbf{I} \sigma_{e}^{2}$, where $\sigma_{u}^{2}$ is the genetic variance, $\sigma_{e}^{2}$ is the residual variance, and $\mathbf{I}$ is an identity matrix.

Estimated variance components were then used to calculate the genomic heritability of each biomarker. The distributions of the residuals of each model were checked for normality using frequency histograms. Residuals of models for BHB, fatty acids, and haptoglobin were positively skewed. To fulfil the assumption of normality for subsequent genetic analyses, a $\log _{10}$ transformation was applied to BHB and haptoglobin concentrations, and a square root transformation was applied to fatty acid concentrations.

Second, a bivariate model was used to estimate the genetic correlation between each pair of serum biomarker traits. For a given pair of biomarkers, the bivariate model was

$$
\left[\begin{array}{l}
\mathbf{y}_{1} \\
\mathbf{y}_{2}
\end{array}\right]=\left[\begin{array}{cc}
\mathbf{X}_{1} & 0 \\
0 & \mathbf{X}_{2}
\end{array}\right]\left[\begin{array}{l}
\mathbf{b}_{1} \\
\mathbf{b}_{2}
\end{array}\right]+\left[\begin{array}{cc}
\mathbf{Z}_{1} & 0 \\
0 & \mathbf{Z}_{2}
\end{array}\right]\left[\begin{array}{l}
\mathbf{u}_{1} \\
\mathbf{u}_{2}
\end{array}\right]+\left[\begin{array}{l}
\mathbf{e}_{1} \\
\mathbf{e}_{2}
\end{array}\right],
$$

where $\mathbf{y}_{i}=$ vector of observations for the $i$ th trait, $\mathbf{b}_{i}$ $=$ vector of fixed effects for the $i$ th trait, $\mathbf{u}_{i}=$ vector of random animal effects for the $i$ th trait, $\mathbf{e}_{i}=$ residual effects for the $i$ th trait, and $\mathbf{X}_{i}$ and $\mathbf{Z}_{i}=$ incidence matrices relating records of the $i$ th trait to fixed and random animal effects, respectively. It was assumed that

$$
\operatorname{var}\left[\begin{array}{l}
\mathbf{u}_{1} \\
\mathbf{u}_{2} \\
\mathbf{e}_{1} \\
\mathbf{e}_{2}
\end{array}\right]=\left[\begin{array}{cccc}
\boldsymbol{g}_{11} \mathbf{G R M} & \boldsymbol{g}_{12} \mathbf{G R M} & 0 & 0 \\
\boldsymbol{g}_{21} \mathbf{G R M} & \boldsymbol{g}_{22} \mathbf{G R M} & 0 & 0 \\
0 & 0 & \boldsymbol{r}_{11} & \boldsymbol{r}_{12} \\
0 & 0 & \boldsymbol{r}_{21} & \boldsymbol{r}_{22}
\end{array}\right]
$$

where $\boldsymbol{\Sigma} \boldsymbol{g}=$ additive genetic (co)variance matrix for animal effect with each element, defined as $\boldsymbol{g}_{11}=$ additive genetic variance for direct effects for trait $1 ; \boldsymbol{g}_{12}$

\begin{tabular}{|c|c|c|c|c|c|c|c|}
\hline \multirow[b]{2}{*}{ Phenotype } & \multirow[b]{2}{*}{$\mathrm{n}$} & \multirow[b]{2}{*}{ Mean } & \multirow[b]{2}{*}{ SD } & \multirow[b]{2}{*}{$\mathrm{CV}$} & \multicolumn{2}{|c|}{$\begin{array}{l}\text { Optimal concentration } \\
\text { of serum metabolites }\end{array}$} & \multirow[b]{2}{*}{ Reference } \\
\hline & & & & & $\begin{array}{l}\text { Lower } \\
\text { threshold }\end{array}$ & $\begin{array}{l}\text { Upper } \\
\text { threshold }\end{array}$ & \\
\hline BHB & 1,393 & 0.48 & 0.22 & 0.46 & - & $1.2 \mathrm{mmol} / \mathrm{L}$ & Compton et al. (2015) \\
\hline Fatty acids & 1,393 & 0.55 & 0.33 & 0.60 & - & $0.7 \mathrm{mmol} / \mathrm{L}$ & Ospina et al. (2010) \\
\hline $\mathrm{Ca}$ & 1,327 & 2.31 & 0.18 & 0.08 & $2.0 \mathrm{mmol} / \mathrm{L}$ & - & DeGaris and Lean (2008) \\
\hline Albumin & 1,294 & 32.79 & 2.95 & 0.09 & $30 \mathrm{~g} / \mathrm{L}$ & - & Whitaker (2004) \\
\hline Globulin & 1,294 & 38.36 & 6.04 & 0.16 & - & $50 \mathrm{~g} / \mathrm{L}$ & Whitaker (2004) \\
\hline Albumin:globulin & 1,294 & 0.88 & 0.17 & 0.19 & 0.84 & - & Kaneko et al. (2008) \\
\hline Haptoglobin & 779 & 0.27 & 0.30 & 1.11 & - & $1.4 \mathrm{~g} / \mathrm{L}$ & Pohl et al. (2015) \\
\hline
\end{tabular}

Table 1. Number of samples (n), phenotypic means, standard deviations, coefficients of variation (CV), and optimal concentration ranges of serum biomarkers of metabolic health of dairy cattle in the first $30 \mathrm{~d}$ of lactation 
$=g_{21}=$ additive genetic covariance between trait 1 and trait $2 ; \boldsymbol{g}_{22}=$ additive genetic variance for direct effects for trait 2; GRM is the genomic relationship matrix among animals; and $\mathbf{R}=$ (co)variance matrix for residual effects, where $\boldsymbol{r}_{11}=$ residual variance for trait $1 ; \boldsymbol{r}_{12}=\boldsymbol{r}_{21}=$ residual covariance between trait 1 and trait 2 ; and $\boldsymbol{r}_{22}=$ residual variance for trait 2 .

Correlations Between Biomarker Genomic $E B V$ and Breeding Values for Health, Fertility, and Production Traits. Genomic EBV (GEBV) for each biomarker trait were predicted using genomic BLUP (GBLUP) in ASReml (Gilmour et al., 2015), using variance components estimated from the univariate model (model [1]). Published EBV for health (survival and SCC), daughter fertility, and milk production (milk, fat, and protein yields), calculated using BLUP from pedigree, cow data, and genomics, were obtained from the Australian routine national genetic evaluations performed by DataGene Ltd. (Bundoora, Australia). We attempted to use the method described in Calo et al. (1973) to correct for the reliability of breeding values; however, this method led to unrealistically high correlations. For this reason, simple Pearson correlations between GEBV and EBV were calculated. Any individual breeding value (GEBV or EBV) with a reliability $<0.1$ was excluded from the analysis.

Genomic Predictions. The accuracy of genomic predictions was assessed in 2 ways. First, empirical prediction accuracy $\left(\mathrm{r}_{e}\right)$ was evaluated using 5-fold cross-validation as proposed by Legarra et al. (2008). This involved randomly dividing the total population into 5 equally sized groups or folds. Data from 1 fold (approximately $20 \%$ of the population) were set aside as a testing set. Data from the remaining 4 folds (approximately $80 \%$ of the population) formed the training set, which was used for model development. The resulting model was then used to predict GEBV for animals in the testing set. This was repeated 5 times, so that all animals appeared in the testing set once. Empirical accuracy was then calculated as the Pearson correlation between the predicted GEBV and actual phenotypic values, corrected for the fixed effects described in model [1]. The corrected phenotypes will include the additive genetic and residual components associated with each phenotype. To calculate predicted accuracies of the true breeding values $\left(\mathrm{r}_{p}\right.$ ) (as opposed to the EBV), the mean correlations between GEBV and corrected phenotypes for each cross-validation fold were divided by the square root of the heritability of the trait (Su et al., 2012).

Second, individual accuracy $\left(\mathrm{r}_{i}\right)$ of individual $i$ was calculated as

$$
\mathrm{r}_{i}=\sqrt{1-\frac{S E_{i}^{2}}{\sigma_{g}^{2} \mathbf{G R M}_{i i}}}
$$

where $S E_{i}$ is the standard error of GEBV of individual $i$, and $\sigma_{g}^{2}$ is the genetic variance of each trait estimated from model [1], adjusted for inbreeding by multiplying by the corresponding diagonal elements in the GRM for each individual $\left(\mathbf{G R M}_{i i}\right)$.

\section{RESULTS}

\section{Model Selection and Genetic Parameters}

We tested 4 functions of DIM as fixed effects in model [1]: linear, linear + quadratic, third-order orthogonal polynomial, or fourth-order orthogonal polynomial. The Akaike information criteria resulting from these models suggested that fatty acids was best fitted with linear DIM, whereas the rest of the traits were best fitted with the third-order orthogonal polynomial function of DIM.

Estimated genomic heritabilities obtained from model [1] are shown in Table 2. Heritability estimates for serum BHB, fatty acids, $\mathrm{Ca}, \mathrm{Mg}$, and urea concentrations were low, at $0.09,0.18,0.07,0.19$, and 0.18 , respectively. Heritabilities of albumin, globulins, and A:G were higher at $0.27,0.46$, and 0.41 , respectively. The estimated heritability of haptoglobin in our data set was close to zero. Standard errors for all heritability estimates were low (0.04 to 0.06).

Genetic and phenotypic correlations between biomarkers, estimated from model [2], are shown in Table 2. The magnitude of estimated genetic correlations varied considerably, ranging from close to 0 (BHB and globulin, and $\mathrm{Ca}$ and globulins) to -0.96 (globulins and A:G). With the exception of correlations between albumin and globulin and A:G, standard errors of all correlations were relatively high (0.12 to 0.44$)$. We observed significant positive genetic correlations between $\mathrm{Ca}$ and albumin $(0.54 \pm 0.31), \mathrm{Mg}$ and urea $(0.44 \pm 0.22), \mathrm{Mg}$ and albumin $(0.29 \pm 0.17)$, and urea and albumin $(0.79$ $\pm 0.16)$. Significant negative genetic correlations were observed between fatty acids and $\mathrm{Ca}(-0.82 \pm 0.44)$, fatty acids and albumin $(-0.29 \pm 0.18)$, and albumin and globulins $(-0.50 \pm 0.12)$. The trend in the direction of genetic correlations was generally favorable; toward lower concentrations of BHB, fatty acids, and globulins, and higher concentrations of $\mathrm{Ca}, \mathrm{Mg}$, urea, albumin, and A:G. This was true for all genetic correlations, except for those between $\mathrm{BHB}$ and $\mathrm{Mg}$, urea and albumin, and fatty acids and globulins. 


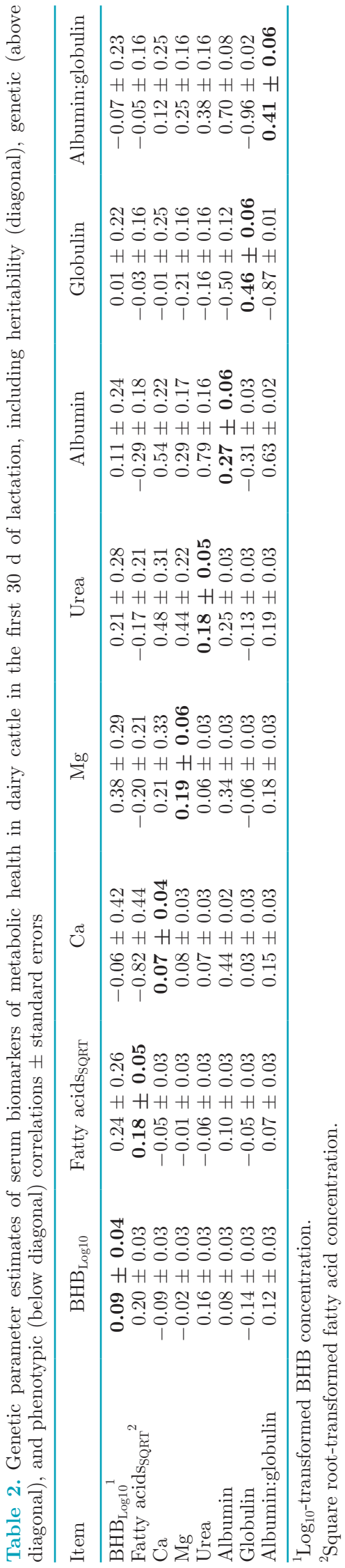

The magnitude of phenotypic correlations varied from 0.01 (between fatty acids and $\mathrm{Mg}$ ) to 0.44 (between Ca and albumin). Standard errors for all phenotypic correlations were small $(\leq 0.03)$. The direction of phenotypic correlations was the same as the direction of genetic correlations for all trait pairs except BHB and $\mathrm{Mg}, \mathrm{BHB}$ and $\mathrm{A}: \mathrm{G}$, fatty acids and albumin, fatty acids and A:G, and globulins and Ca. Of these, the only statistically significant genetic correlation was between fatty acids and albumin.

\section{Correlations Between Biomarker GEBV and Breeding Values for Health, Fertility, and Production Traits}

Pearson correlations between biomarker GEBV and EBV for survival, SCC, daughter fertility, and milk production traits are shown in Table 3 . The magnitudes of correlations between biomarker GEBV and health and fertility EBV were low to moderate: 0.15 to 0.45 for survival, 0.07 to 0.32 for SCC, and 0.11 to 0.37 for daughter fertility. The direction of correlations was favorable for all pairs of breeding values; BHB, fatty acids, and globulins GEBV were negatively correlated with health and fertility EBV, whereas $\mathrm{Ca}, \mathrm{Mg}$, urea, albumin, and A:G GEBV were positively correlated with health and fertility EBV.

The magnitude of correlations between biomarker GEBV and EBV for production traits (milk, fat, and protein yields) were small (0.01 to 0.15). We observed small positive correlations between breeding values for milk yield and albumin (0.11), milk yield and urea (0.10), milk fat yield and BHB (0.15), and milk fat yield and urea (0.10). Small negative correlations were observed between the breeding values for milk yield and BHB (-0.10), milk yield and $\mathrm{Mg}(-0.06)$, milk protein yield and $\mathrm{Mg}(-0.13)$, and milk fat yield and $\mathrm{Ca}(-0.10)$.

\section{Accuracy of Genomic Predictions}

Empirical accuracies and means of individual accuracies of genomic predictions resulting from univariate models are shown in Table 4. Empirical accuracies for all models were low, ranging from 0.05 to 0.27 , and increased with increasing trait heritability. Expected empirical accuracies of true breeding values, estimated by correcting empirical accuracies for trait heritabilities, were between 0.20 and 0.40 . Mean individual accuracies were greater than empirical accuracies for all traits ( 0.31 to 0.51 ), but the results of the 2 methods were in agreement (i.e., the correlation between the 2 sets of accuracies was 0.89). 
Table 3. Pearson correlations between genomic EBV for serum biomarkers of early lactation health, and Australian breeding values for survival, SCC, daughter fertility, and milk, fat, and protein yields

\begin{tabular}{|c|c|c|c|c|c|c|c|}
\hline \multirow[b]{2}{*}{ Biomarker } & \multirow[b]{2}{*}{$\mathrm{N}$} & \multicolumn{6}{|c|}{ EBV } \\
\hline & & Survival & SCC & $\begin{array}{l}\text { Daughter } \\
\text { fertility }\end{array}$ & $\begin{array}{l}\text { Milk } \\
\text { yield }\end{array}$ & $\begin{array}{l}\text { Milk protein } \\
\text { yield }\end{array}$ & $\begin{array}{l}\text { Milk fat } \\
\text { yield }\end{array}$ \\
\hline Fatty acids ${ }_{\mathrm{SQRT}}{ }^{2}$ & 1,176 & -0.27 & -0.16 & -0.20 & -0.07 & 0.01 & 0.04 \\
\hline $\mathrm{Ca}$ & 719 & 0.15 & 0.07 & 0.24 & 0.00 & 0.07 & -0.10 \\
\hline $\mathrm{Mg}$ & 1,129 & 0.21 & 0.15 & 0.25 & -0.06 & -0.13 & 0.03 \\
\hline Urea & 1,161 & 0.38 & 0.23 & 0.26 & 0.10 & 0.05 & 0.10 \\
\hline Albumin:globulin & 1,321 & 0.36 & 0.26 & 0.30 & 0.07 & -0.01 & 0.01 \\
\hline
\end{tabular}

${ }^{1} \log _{10}$-transformed BHB concentration.

${ }^{2}$ Square root-transformed fatty acid concentration.

\section{DISCUSSION}

The genetic parameters of metabolic disorders in early-lactation dairy cows, as defined by producer or veterinarian-recorded health data, have been studied extensively. Few studies have investigated the genetic parameters of serum biomarkers of health, and to the best of the authors' knowledge, this is the first study to investigate and report the genetic parameters of a metabolic profile that covers a range of biomarkers of energy balance, macromineral status, protein nutritional status, and immune status. Furthermore, we believe this is the first study to report the accuracies of genomic predictions of these traits and marks the start of an emerging area for genomic prediction to reduce early-lactation disease in dairy cows.

\section{Heritability Estimates of Serum Biomarkers of Health}

Our results indicate that genetic variation exists for all biomarkers studied except haptoglobin. Heritability estimates were consistent with the literature for $\mathrm{Mg}$ (Tsiamadis et al., 2016a), albumin, globulins, and A:G (Cecchinato et al., 2018). The estimated heritability of fatty acid concentration in our study was consistent with the findings of Oikonomou et al. (2008b); however, it should be noted that our heritability estimate is for square root-transformed fatty acid concentrations, not raw concentrations. No reports of the heritability of serum urea concentration were found in the literature. However, our results are consistent with the reported heritability of MUN concentration (Mitchell et al., 2005), which is linearly correlated with serum urea concentration (Moore and Varga, 1996).

The genetic parameters of BHB have been more widely reported than those of the other biomarkers investigated in this study. Reported heritabilities of BHB concentration vary considerably, from $0.073 \pm$ 0.77 (Tsiamadis et al., 2016b) to $0.40 \pm 0.06$ (Oikonomou et al., 2008b). However, care must be taken when interpreting results because of significant differences in study design (in particular, stage of lactation), math-

Table 4. Accuracies of genomic EBV for serum metabolic biomarkers including empirical accuracies for each of 5 cross-validation folds, mean empirical accuracy $(\mu)$, predicted accuracy of the true breeding value $(\mu / h)$, and the mean of individual accuracies calculated from predicted error variance $\left(\mathrm{r}_{\mathrm{t}}\right)$

\begin{tabular}{|c|c|c|c|c|c|c|c|c|}
\hline \multirow[b]{2}{*}{ Trait } & \multicolumn{5}{|c|}{ Cross-validation fold } & \multirow[b]{2}{*}{$\mu$} & \multirow[b]{2}{*}{$\mu / \mathrm{h}$} & \multirow[b]{2}{*}{$r_{t}$} \\
\hline & 1 & 2 & 3 & 4 & 5 & & & \\
\hline $\mathrm{BHB}_{\log 10}^{1}$ & 0.04 & 0.08 & 0.14 & 0.09 & 0.08 & 0.09 & 0.29 & 0.34 \\
\hline Fatty acids ${ }_{\mathrm{SORT}}{ }^{2}$ & 0.15 & 0.11 & 0.14 & 0.16 & 0.19 & 0.15 & 0.36 & 0.41 \\
\hline Calcium & 0.02 & 0.09 & 0.12 & -0.09 & 0.13 & 0.05 & 0.20 & 0.31 \\
\hline Magnesium & 0.09 & 0.01 & 0.13 & 0.17 & 0.22 & 0.12 & 0.28 & 0.41 \\
\hline Urea & 0.24 & 0.13 & 0.18 & 0.02 & 0.06 & 0.13 & 0.30 & 0.41 \\
\hline Albumin & 0.18 & 0.26 & 0.25 & 0.15 & 0.14 & 0.20 & 0.38 & 0.44 \\
\hline Globulin & 0.24 & 0.28 & 0.30 & 0.29 & 0.23 & 0.27 & 0.40 & 0.51 \\
\hline Albumin:globulin & 0.24 & 0.26 & 0.30 & 0.28 & 0.19 & 0.25 & 0.40 & 0.49 \\
\hline
\end{tabular}

${ }^{1} \log _{10}$-transformed BHB concentration.

${ }^{2}$ Square root-transformed fatty acid concentration. 
ematical transformations of metabolite concentrations, and the genetic models used. Our study and results are most comparable to those of Weigel et al. (2017) and van der Drift et al. (2012), who reported heritabilities of $0.093 \pm 0.045$ for square root-transformed BHB, and $0.17 \pm 0.06$ for $\log _{10}$-transformed BHB, respectively. Oikonomou et al. (2008b) demonstrated that the heritability of serum BHB concentration is greatest in the week immediately after calving and decreases rapidly over the first 7 wk of lactation. In our study, only 209 cows were in the first week of lactation at the time of sampling, and we expect that increasing the number of animals sampled during the suggested high-risk period will improve heritabilities.

The heritability of $\mathrm{Ca}$ in our data set was significantly less than that reported by Tsiamadis et al. (2016a), who found that the heritability of serum $\mathrm{Ca}$ at $\mathrm{d} 1,2$, 4 , and 8 postpartum ranged from $0.23 \pm 0.02$ to $0.32 \pm$ 0.03. In adult cows, homeostatic mechanisms maintain serum Ca concentrations between 2.1 and $2.5 \mathrm{mmol} / \mathrm{L}$ (Goff, 2008). However, serum Ca concentrations decline in the periparturient period and reach their nadir 12 to $24 \mathrm{~h}$ postcalving before rapidly returning to normal physiological levels once homeostatic mechanisms are restored (Kimura et al., 2006). It is likely that our low heritability estimate is the result of having sampled only 14 cows during this period of greatest phenotypic variability. Subclinical hypocalcemia, defined as serum Ca concentrations between 1.38 and $2.1 \mathrm{mmol} / \mathrm{L}$ and which increases the risk of other metabolic and infectious diseases, occurs most commonly in this 12-h window (Goff, 2008). We therefore plan to collect many more samples from animals during this period in future investigations.

Our study also differed from others that report higher heritabilities, in that we took only a single sample from each animal. It is likely that taking serial samples from individual animals across the early-lactation period and using random regression models would increase heritability estimates. This was not possible in the current study because all farms operated a seasonal calving system with large numbers of cows calving in a short period, making multiple visits impractical. These results demonstrate the importance of careful trait definition when investigating genetic parameters of health traits in the transition period. We plan to collect more samples during the periods of highest phenotypic and genetic variation in the future (e.g., 0 to $1 \mathrm{DIM}$ for $\mathrm{Ca}$, 0 to 7 DIM for BHB).

The heritability of haptoglobin in our data set was close to 0 . Haptoglobin is a positive acute phase protein produced by the liver (Morimatsu et al., 1991), which is used as an indicator of inflammation in cattle
(Horadagoda et al., 1999). The low genetic variance of haptoglobin concentration in our research was surprising, especially given the relatively high heritability of albumin, another acute phase protein produced by the liver (Jain et al., 2011), and of globulins and A:G, other indicators of inflammation (Burke et al., 2010). One possible reason for this result is the small sample size $(\mathrm{n}=779)$, and we consider that more data are required to validate this finding. An alternative to haptoglobin may be A:G, which has been used as a nonspecific indicator of immune status (Piccinini et al., 2004). Our results indicate that A:G may be a promising biomarker for genetic selection of improved immune competence, similar to selecting for humoral immune response, which has been demonstrated to improve overall animal health and resilience (De La Paz, 2008; Thompson-Crispi et al., 2012b).

\section{Genetic Correlations Between Serum Biomarkers of Health}

The trend in the direction of genetic correlations between biomarkers was mostly favorable, suggesting that selection for more optimal concentrations of one biomarker may result in improvements in the concentrations of others. Optimal concentration ranges for health biomarkers, based on epidemiological associations between biomarker concentrations and health, production, and fertility outcomes, have been studied and reported extensively (Whitaker, 2004; Overton et al., 2017) and are summarized in Table 1. Our results are consistent with previous studies that reported favorable genetic correlations between the occurrence of clinical metabolic diseases such as milk fever and ketosis (Heringstad et al., 2005). The most favorable correlations were those of fatty acids with albumin and $\mathrm{Ca}$, and albumin with $\mathrm{Ca}, \mathrm{Mg}$, urea, and globulins. These results suggest that albumin and fatty acids may be potential biomarkers for early lactation health. Albumin is an abundant protein synthesized in the liver that is responsible for several important biological functions, such as maintaining circulating blood volume; transporting metabolites, hormones, fatty acids, and other nutrients; and controlling biologically active concentrations of $\mathrm{Ca}$ in the bloodstream (Majorek et al., 2012). Given these diverse biological functions, it follows that higher concentrations of albumin are genetically associated with improved animal health and fertility. Alternatively, it may be that a higher albumin concentration is an indicator of good liver function, which is known to be important for early lactation health (Bionaz et al., 2007). Fatty acid concentration is an indicator of negative energy balance, and elevated $(>0.57 \mathrm{mmol} / \mathrm{L})$ 
concentrations in the first 2 wk of lactation are associated with an increased risk of subsequent negative health events (Ospina et al., 2010; Chapinal et al., 2012; Sordillo and Raphael, 2013). Selecting for animals that mobilize less body fat may therefore lead to a decrease in other early-lactation diseases.

We could find relatively few reports in the scientific literature of genetic correlations between metabolic profile biomarkers in serum. Our results did not support reports of unfavorable correlations between serum BHB and albumin and A:G (Cecchinato et al., 2018). This may be because data in that study were not restricted to early lactation. Although the magnitude of correlations in our data set ranged considerably, standard error estimates for many correlations were relatively large, and many correlations were not significantly different from zero. This is consistent with the findings of Tsiamadis et al. (2016a), who found that genetic correlations between $\mathrm{Ca}, \mathrm{P}, \mathrm{Mg}$, and $\mathrm{K}$ concentrations in the first $8 \mathrm{~d}$ of lactation were not significantly different from zero. The large standard errors we report are likely due, in part, to the small sample size, and we consider that more data are required to better understand these genetic relationships. Despite this, the trends in our data support previous findings that some early-lactation metabolic disorders share some common genetic basis, and that there may be potential to select for increased resilience in the form of improved metabolic stability in early lactation.

In addition to larger data sets, alternative approaches may be required to better understand the complex genetic relationships between metabolic diseases in early lactation. One approach is that taken by $\mathrm{Ha}$ et al. (2015), who used gene-based mapping and pathway analysis to demonstrate that BHB, fatty acid, and glucose concentrations share genetic pathways associated with steroid and lipid metabolism. Another approach could be to use metabolomic techniques, such as liquid chromatography-mass spectroscopy and nuclear magnetic resonance spectroscopy, in conjunction with genome-wide association studies, to identify novel biomarkers and genes associated with early-lactation health or disease.

\section{Correlations Between Biomarker GEBV and Health, Fertility, and Milk Production Breeding Values}

Correlations between biomarker GEBV and health (survival and SCC) and fertility EBV were low to moderate, offering further evidence that complex genetic relationships exist between the etiopathology of metabolic, inflammatory, and fertility disorders in early lactation. Interestingly, all correlations were favorable, with more-optimal biomarker concentrations being associated with higher breeding values for survival, SCC, and daughter fertility.

Correlations between breeding values should be viewed as indicative of genetic correlations, and it should be noted that phenotypic data from some of the cows in our study may also have been used in the DataGene evaluation. However, it was encouraging that our results were consistent with the findings of Oikonomou et al. (2008a), who reported favorable genetic correlations between fatty acid concentrations and fertility traits such as calving interval and absence of reproductive problems, and those of Koeck et al. (2014), who reported favorable correlations between milk BHB and SCC, fertility, and herd life. Cecchinato et al. (2018) reported only nonsignificant correlations between SCC and BHB $(-0.081 \pm 0.49)$ and SCC and globulins $(-0.108 \pm 0.54)$, and nonsignificant correlations between SCC and albumin $(0.423 \pm 0.52)$ and SCC and A:G $(0.350 \pm 0.51)$. Again, this could be attributed to differences in study design and lactation period. Of particular interest were the moderate correlations we observed between health and fertility EBV, and GEBV for fatty acids, albumin, globulins, and A:G. These results are consistent with favorable correlations among these biomarkers. Multi-trait genome-wide association studies may help improve our understanding of these complex genetic relationships.

In contrast to correlations with health and fertility traits, correlations between biomarker GEBV and EBV for production traits were low $(\leq 0.15)$, suggesting that selection for improved metabolic health in early lactation may not have a large effect on milk production. In contrast, Cecchinato et al. (2018) reported significant genetic correlations between BHB and milk yield (0.716 $\pm 0.21)$, total protein and fat percentage $(-0.854 \pm$ $0.18)$, and albumin and fat percentage $(-0.894 \pm 0.17)$, although it should be reiterated that this study was not restricted to biomarker concentrations in early lactation. Belay et al. (2017) found positive genetic correlations between BHB predicted from milk mid-infrared spectra, and milk yield $(0.277 \pm 0.016)$, milk protein $(0.107 \pm 0.017)$, and milk fat $(0.248 \pm 0.016)$. These differing results are consistent with the variability in reported genetic correlations between producer- or veterinarian-recorded metabolic diseases traits and milk production traits (Pryce et al., 2016). Koeck et al. (2014) reported a moderate genetic correlation between milk BHB concentration and producer-recorder clinical ketosis occurrence $(0.48 \pm 0.35)$. Such favorable genetic correlations between biomarker concentrations and clinical disease data should enable the assembly of much larger data sets, which are required to better understand these relationships. 


\section{Accuracy of Genomic Predictions of Serum Biomarkers}

The accuracies of genomic predictions observed are commensurate with a small female reference population and low-to-moderate trait heritabilities (GonzalezRecio et al., 2014). Weigel et al. (2017) reported greater empirical genomic prediction accuracies for BHB concentrations (0.29 to 0.36); however, those results are not comparable to results of the current study because their predicted phenotypes included model solutions for the herd-year-season contemporary group and parity, in addition to the GEBV; that is, their prediction was of the expressed phenotype. We expect that increasing the size of the reference population and refining trait definitions to maximize heritabilities should improve accuracies. Given the cost and logistical challenges of blood sampling large numbers of cows, one method to dramatically increase the number of phenotypes may be to use mid-infrared spectroscopy of milk to predict serum biomarker concentrations (Belay et al., 2017). Additionally, this may be a trait area that is suitable for sharing of data sets. A comparable example is genomic prediction of DMI using multi-country populations; for example, de Haas et al. (2015). They assembled a data set of DMI records from $\sim 9,000$ cows in 10 populations to show that genomic prediction accuracies were always higher when multi-country reference sets were used compared with within-country data sets. Finally, high-throughput metabolomic methods such as nuclear magnetic resonance spectroscopy and liquid chromatography-mass spectroscopy may help to identify novel and more accurate biomarkers of health and disease; if these data can be used to facilitate identification of important genetic variants, this may also help to improve genomic prediction accuracies.

\section{CONCLUSIONS}

We investigated genetic parameters of serum biomarkers of health using data collected from a genotyped female reference population. We found that biomarkers of energy balance (BHB and fatty acids), protein nutritional status (albumin and urea), macromineral status ( $\mathrm{Ca}$ and $\mathrm{Mg}$ ), and immune status (globulins and $\mathrm{A}: \mathrm{G}$ ) are heritable traits, and that genomic selection to improve the concentrations of these biomarkers should be possible. Of the biomarkers investigated, fatty acids, albumin, and A:G are of particular interest because of their (1) significant phenotypic associations with other early-lactation diseases, (2) moderate to high heritabilities, (3) promising genomic prediction accuracies, (4) favorable estimated genetic correlations with other biomarkers, and (5) promising correlations between GEBV and existing EBV for health, fertility, and production traits.

\section{ACKNOWLEDGMENTS}

We thank DairyBio, jointly funded by Dairy Australia (Melbourne, Australia) and Agriculture Victoria (Melbourne, Australia), for funding this project and T. Luke's PhD project. The authors also thank Di Mapleson, Brigid Ribaux, and the staff at Ellinbank Dairy Research Centre (Ellinbank, Australia) for their technical expertise and assistance; Erika Oakes, Miranda Clark, and the staff at Datagene (Bundoora, Australia) for their work coordinating this study; and the farmers who took part in this project.

\section{REFERENCES}

Abdelsayed, M., M. Haile-Mariam, and J. E. Pryce. 2017. Genetic parameters for health traits using data collected from genomic information nucleus herds. J. Dairy Sci. 100:9643-9655. https:// doi.org/10.3168/jds.2017-12960.

Anderson, D. E. 2009. Current Veterinary Therapy: Food Animal Practice. Saunders/Elsevier, St. Louis, MO.

Belay, T. K., M. Svendsen, Z. M. Kowalski, and T. Ådnøy. 2017. Genetic parameters of blood $\beta$-hydroxybutyrate predicted from milk infrared spectra and clinical ketosis, and their associations with milk production traits in Norwegian Red cows. J. Dairy Sci. 100:6298-6311. https://doi.org/10.3168/jds.2016-12458.

Bionaz, M., E. Trevisi, L. Calamari, F. Librandi, A. Ferrari, and G. Bertoni. 2007. Plasma paraoxonase, health, inflammatory conditions, and liver function in transition dairy cows. J. Dairy Sci. 90:1740-1750. https://doi.org/10.3168/jds.2006-445.

Boichard, D., and M. Brochard. 2012. New phenotypes for new breeding goals in dairy cattle. Animal 6:544-550. https://doi.org/10 $.1017 /$ S1751731112000018.

Burke, C. R., S. Meier, S. McDougall, C. Compton, M. Mitchell, and J. R. Roche. 2010. Relationships between endometritis and metabolic state during the transition period in pasture-grazed dairy cows. J. Dairy Sci. 93:5363-5373. https://doi.org/10.3168/jds.2010-3356.

Calo, L. L., R. E. McDowell, L. Dale Van Vleck, and P. D. Miller. 1973. Genetic aspects of beef production among Holstein-Friesians pedigree selected for milk production. J. Anim. Sci. 37:676-682. https://doi.org/10.2527/jas1973.373676x.

Cecchinato, A., T. Bobbo, P. L. Ruegg, L. Gallo, G. Bittante, and S. Pegolo. 2018. Genetic variation in serum protein pattern and blood $\beta$-hydroxybutyrate and their relationships with udder health traits, protein profile, and cheese-making properties in Holstein cows. J. Dairy Sci. 101:11108-11119. https://doi.org/10.3168/jds .2018-14907.

Chapinal, N., S. J. Leblanc, M. E. Carson, K. E. Leslie, S. Godden, M. Capel, J. E. Santos, M. W. Overton, and T. F. Duffield. 2012. Herd-level association of serum metabolites in the transition period with disease, milk production, and early lactation reproductive performance. J. Dairy Sci. 95:5676-5682. https://doi.org/10 $.3168 /$ jds.2011-5132.

Compton, C. W., L. Young, and S. McDougall. 2015. Subclinical ketosis in post-partum dairy cows fed a predominantly pasture-based diet: Defining cut-points for diagnosis using concentrations of betahydroxybutyrate in blood and determining prevalence. N. Z. Vet. J. 63:241-248. https://doi.org/10.1080/00480169.2014.999841.

de Haas, Y., J. E. Pryce, M. P. L. Calus, E. Wall, D. P. Berry, P. Løvendahl, N. Krattenmacher, F. Miglior, K. Weigel, D. Spurlock, K. A. Macdonald, B. Hulsegge, and R. F. Veerkamp. 2015. Genomic prediction of dry matter intake in dairy cattle from an international data set consisting of research herds in Europe, North 
America, and Australasia. J. Dairy Sci. 98:6522-6534. https://doi .org/10.3168/jds.2014-9257.

De La Paz, J. M. 2008. Using humoral and cellular response to novel antigens in periparturient dairy cows as a measure of genetic disease resistance in dairy cows. MSc Thesis. Veterinary Medicine Dept., University of Florida, Gainesville.

DeGaris, P. J., and I. J. Lean. 2008. Milk fever in dairy cows: A review of pathophysiology and control principles. Vet. J. 176:58-69. https: //doi.org/10.1016/j.tvjl.2007.12.029.

Dumas, B. T., W. A. Watson, and H. G. Biggs. 1997. Albumin standards and the measurement of serum albumin with bromocresol green. Clin. Chim. Acta 258:21-30. https://doi.org/10.1016/s0009 $-8981(96) 06447-9$

Egger-Danner, C., J. B. Cole, J. E. Pryce, N. Gengler, B. Heringstad, A. Bradley, and K. F. Stock. 2015. Invited review: Overview of new traits and phenotyping strategies in dairy cattle with a focus on functional traits. Animal 9:191-207. https://doi.org/10.1017/ S1751731114002614.

Erbe, M., B. J. Hayes, L. K. Matukumalli, S. Goswami, P. J. Bowman, C. M. Reich, B. A. Mason, and M. E. Goddard. 2012. Improving accuracy of genomic predictions within and between dairy cattle breeds with imputed high-density single nucleotide polymorphism panels. J. Dairy Sci. 95:4114-4129. https://doi.org/10.3168/jds .2011-5019.

Gilmour, A. R., B. J. Gogel, B. R. Cullis, S. J. Welham, and R Thompson. 2015. ASReml User Guide. Release 4.1 Structural Specification. VSN International Ltd., Hemel Hempstead, UK. www.vsni.co.uk.

Goff, J. P. 2008. The monitoring, prevention, and treatment of milk fever and subclinical hypocalcemia in dairy cows. Vet. J. 176:50-57. https://doi.org/10.1016/j.tvjl.2007.12.020.

Gonzalez-Recio, O., M. P. Coffey, and J. E. Pryce. 2014. On the value of the phenotypes in the genomic era. J. Dairy Sci. 97:7905-7915. https://doi.org/10.3168/jds.2014-8125.

Gornall, A. G., C. J. Bardawill, and M. M. David. 1949. Determination of serum proteins by means of the biuret reaction. J. Biol. Chem. 177:751-766

Ha, N.-T., J. J. Gross, A. van Dorland, J. Tetens, G. Thaller, M. Schlather, R. Bruckmaier, and H. Simianer. 2015. Gene-based mapping and pathway analysis of metabolic traits in dairy cows. PLoS One 10:e122325. https://doi.org/10.1371/journal.pone .0122325 .

Heringstad, B., Y. M. Chang, D. Gianola, and G. Klemetsdal. 2005. Genetic analysis of clinical mastitis, milk fever, ketosis, and retained placenta in three lactations of Norwegian red cows. J. Dairy Sci. 88:3273-3281. https://doi.org/10.3168/jds.S0022 $-0302(05) 73010-1$

Horadagoda, N. U., K. M. Knox, H. A. Gibbs, S. W. Reid, A. Horadagoda, S. E. Edwards, and P. D. Eckersall. 1999. Acute phase proteins in cattle: Discrimination between acute and chronic inflammation. Vet. Rec. 144:437-441. https://doi.org/10.1136/vr 144.16.437.

Jain, S., V. Gautam, and S. Naseem. 2011. Acute-phase proteins: As diagnostic tool. J. Pharm. Bioallied Sci. 3:118-127. https://doi .org/10.4103/0975-7406.76489

Jamrozik, J., A. Koeck, G. J. Kistemaker, and F. Miglior. 2016. Multiple-trait estimates of genetic parameters for metabolic disease traits, fertility disorders, and their predictors in Canadian Holsteins. J. Dairy Sci. 99:1990-1998. https://doi.org/10.3168/jds .2015-10505

Janssen, J. W., and A. R. Helbing. 1991. Arsenazo III: An improvement of the routine calcium determination in serum. Eur. J. Clin. Chem. Clin. Biochem. 29:197-201.

Kaneko, J. J., J. W. Harvey, and M. L. Bruss. 2008. Normal concentrations of blood constituents in domestic animals. Pages 873-904 in Clinical Biochemistry of Domestic Animals. 6th ed. Academic Press/Elsevier, Burlington, MA

Kimura, K., T. A. Reinhardt, and J. P. Goff. 2006. Parturition and hypocalcemia blunts calcium signals in immune cells of dairy cattle. J. Dairy Sci. 89:2588-2595. https://doi.org/10.3168/jds.S0022 $-0302(06) 72335-9$.
Koeck, A., J. Jamrozik, F. S. Schenkel, R. K. Moore, D. M. Lefebvre, D. F. Kelton, and F. Miglior. 2014. Genetic analysis of milk $\beta$-hydroxybutyrate and its association with fat-to-protein ratio, body condition score, clinical ketosis, and displaced abomasum in early first lactation of Canadian Holsteins. J. Dairy Sci. 97:72867292. https://doi.org/10.3168/jds.2014-8405.

LeBlanc, S. J., K. D. Lissemore, D. F. Kelton, T. F. Duffield, and K. E. Leslie. 2006. Major advances in disease prevention in dairy cattle. J. Dairy Sci. 89:1267-1279. https://doi.org/10.3168/jds.S0022 $-0302(06) 72195-6$.

Legarra, A., C. Robert-Granie, E. Manfredi, and J. M. Elsen. 2008. Performance of genomic selection in mice. Genetics 180:611-618. https://doi.org/10.1534/genetics.108.088575.

Luke, T. D. W., S. Rochfort, W. J. Wales, V. Bonfatti, L. Marett, and J. E. Pryce. 2019. Metabolic profiling of early-lactation dairy cows using milk mid-infrared spectra. J. Dairy Sci. 102:1747-1760. https://doi.org/10.3168/jds.2018-15103.

Lyons, D. T., A. E. Freeman, and A. L. Kuck. 1991. Genetics of health traits in Holstein cattle. J. Dairy Sci. 74:1092-1100. https://doi .org/10.3168/jds.S0022-0302(91)78260-X.

Macrae, A. I., D. A. Whitaker, E. Burrough, A. Dowell, and J. M. Kelly. 2006. Use of metabolic profiles for the assessment of dietary adequacy in UK dairy herds. Vet. Rec. 159:655-661. https://doi .org/10.1136/vr.159.20.655.

Majorek, K. A., P. J. Porebski, A. Dayal, M. D. Zimmerman, K. Jablonska, A. J. Stewart, M. Chruszcz, and W. Minor. 2012. Structural and immunologic characterization of bovine, horse, and rabbit serum albumins. Mol. Immunol. 52:174-182. https://doi .org/10.1016/j.molimm.2012.05.011.

Makimura, S., and N. Suzuki. 1982. Quantitative determination of bovine serum haptoglobin and its elevation in some inflammatory diseases. Nihon Juigaku Zasshi 44:15-21.

McArt, J. A. A., D. V. Nydam, and G. R. Oetzel. 2012. Epidemiology of subclinical ketosis in early lactation dairy cattle. J. Dairy Sci. 95:5056-5066. https://doi.org/10.3168/jds.2012-5443.

McArt, J. A. A., D. V. Nydam, G. R. Oetzel, T. R. Overton, and P. A. Ospina. 2013. Elevated non-esterified fatty acids and $\beta$-hydroxybutyrate and their association with transition dairy cow performance. Vet. J. 198:560-570. https://doi.org/10.1016/j.tvjl 2013.08.011.

McArt, J. A. A., D. V. Nydam, and M. W. Overton. 2015. Hyperketonemia in early lactation dairy cattle: A deterministic estimate of component and total cost per case. J. Dairy Sci. 98:2043-2054. https://doi.org/10.3168/jds.2014-8740.

McMurray, C. H., W. J. Blanchflower, and D. A. Rice. 1984. Automated kinetic method for D-3-hydroxybutyrate in plasma or serum. Clin. Chem. 30:421-425.

Mitchell, R. G., G. W. Rogers, C. D. Dechow, J. E. Vallimont, J. B. Cooper, U. Sander-Nielsen, and J. S. Clay. 2005. Milk urea nitrogen concentration: Heritability and genetic correlations with reproductive performance and disease. J. Dairy Sci. 88:4434-4440. https://doi.org/10.3168/jds.S0022-0302(05)73130-1.

Moore, D. A., and G. Varga. 1996. BUN and MUN: Urea nitrogen testing in dairy cattle. Compend. Contin. Educ. Vet. 18:712-720.

Morimatsu, M., B. Syuto, N. Shimada, T. Fujinaga, S. Yamamoto, M. Saito, and M. Naiki. 1991. Isolation and characterization of bovine haptoglobin from acute phase sera. J. Biol. Chem. 266:1183311837.

NHMRC (National Health and Medical Research Council). 2013. Australian code for the care and use of animals for scientific purposes. 8th ed. NHMRC Publications, Canberra, Australia.

Neuenschwander, T. F., F. Miglior, J. Jamrozik, O. Berke, D. F. Kelton, and L. R. Schaeffer. 2012. Genetic parameters for producerrecorded health data in Canadian Holstein cattle. Animal 6:571578. https://doi.org/10.1017/S1751731111002059.

Nguyen, T. T. T., P. J. Bowman, M. Haile-Mariam, J. E. Pryce, and B. J. Hayes. 2016. Genomic selection for tolerance to heat stress in Australian dairy cattle. J. Dairy Sci. 99:2849-2862. https://doi .org/10.3168/jds.2015-9685.

Oikonomou, G., G. Arsenos, G. E. Valergakis, A. Tsiaras, D. Zygoyiannis, and G. Banos. 2008a. Genetic relationship of body energy 
and blood metabolites with reproduction in Holstein cows. J. Dairy Sci. 91:4323-4332. https://doi.org/10.3168/jds.2008-1018.

Oikonomou, G., G. E. Valergakis, G. Arsenos, N. Roubies, and G. Banos. 2008b. Genetic profile of body energy and blood metabolic traits across lactation in primiparous Holstein cows. J. Dairy Sci. 91:2814-2822. https://doi.org/10.3168/jds.2007-0965.

Ospina, P. A., D. Nydam, T. Stokol, and T. Overton. 2010. Associations of elevated nonesterified fatty acids and $\beta$-hydroxybutyrate concentrations with early lactation reproductive performance and milk production in transition dairy cattle in the northeastern United States. J. Dairy Sci. 93:1596-1603. https://doi.org/10.3168/jds .2009-2852

Østerås, O., H. Solbu, A. O. Refsdal, T. Roalkvam, O. Filseth, and A. Minsaas. 2007. Results and evaluation of thirty years of health recordings in the Norwegian dairy cattle population. J. Dairy Sci. 90:4483-4497. https://doi.org/10.3168/jds.2007-0030.

Overton, T. R., J. A. A. McArt, and D. V. Nydam. 2017. A 100-Year Review: Metabolic health indicators and management of dairy cattle. J. Dairy Sci. 100:10398-10417. https://doi.org/10.3168/jds .2017-13054

Parker Gaddis, K. L., J. B. Cole, J. S. Clay, and C. Maltecca. 2014. Genomic selection for producer-recorded health event data in US dairy cattle. J. Dairy Sci. 97:3190-3199. https://doi.org/10.3168/ jds.2013-7543.

Piccinini, R., E. Binda, M. Belotti, G. Casirani, and A. Zecconi. 2004. The evaluation of non-specific immune status of heifers in field conditions during the periparturient period. Vet. Res. 35:539-550. https://doi.org/10.1051/vetres:2004030.

Pohl, A., O. Burfeind, and W. Heuwieser. 2015. The associations between postpartum serum haptoglobin concentration and metabolic status, calving difficulties, retained fetal membranes, and metritis. J. Dairy Sci. 98:4544-4551. https://doi.org/10.3168/jds.2014-9181.

Pryce, J. E., J. Arias, P. J. Bowman, S. R. Davis, K. A. Macdonald, G. C. Waghorn, W. J. Wales, Y. J. Williams, R. J. Spelman, and B. J. Hayes. 2012. Accuracy of genomic predictions of residual feed intake and 250-day body weight in growing heifers using 625,000 single nucleotide polymorphism markers. J. Dairy Sci. 95:2108 2119. https://doi.org/10.3168/jds.2011-4628.

Pryce, J. E., K. L. Parker Gaddis, A. Koeck, C. Bastin, M. Abdelsayed, N. Gengler, F. Miglior, B. Heringstad, C. Egger-Danner, K. F. Stock, A. J. Bradley, and J. B. Cole. 2016. Invited review: Opportunities for genetic improvement of metabolic diseases. J. Dairy Sci. 99:6855-6873. https://doi.org/10.3168/jds.2016-10854.

R Core Team. 2019. R: A language and environment for statistical computing. R Foundation for Statistical Computing, Vienna, Austria. https://www.R-project.org/.

Sordillo, L. M., and W. Raphael. 2013. Significance of metabolic stress, lipid mobilization, and inflammation on transition cow disorders. Vet. Clin. North Am. Food Anim. Pract. 29:267-278. https://doi .org/10.1016/j.cvfa.2013.03.002.

$\mathrm{Su}$, G., O. F. Christensen, T. Ostersen, M. Henryon, and M. S. Lund. 2012. Estimating additive and non-additive genetic variances and predicting genetic merits using genome-wide dense single nucleotide polymorphism markers. PLoS One 7:e45293. https://doi.org/ 10.1371/journal.pone.0045293.

Suthar, V. S., J. Canelas-Raposo, A. Deniz, and W. Heuwieser. 2013. Prevalence of subclinical ketosis and relationships with postpartum diseases in European dairy cows. J. Dairy Sci. 96:2925-2938. https://doi.org/10.3168/jds.2012-6035.
Svoboda, V., and V. Chromý. 1971. A spectrophotometric study of the magnesium-xylidyl blue II complex: Optimal conditions for the determination of magnesium. Anal. Chim. Acta 54:121-131. https: //doi.org/10.1016/S0003-2670(01)81862-6.

Thompson-Crispi, K., R. Ventura, F. Schenkel, F. Miglior, and B. Mallard. 2012a. Genomic selection for enhanced immune response to improve dairy cattle health. Genome 55:721.

Thompson-Crispi, K. A., A. Sewalem, F. Miglior, and B. A. Mallard. 2012b. Genetic parameters of adaptive immune response traits in Canadian Holsteins. J. Dairy Sci. 95:401-409. https://doi.org/10 $.3168 /$ jds.2011-4452.

Tsairidou, S., J. A. Woolliams, A. R. Allen, R. A. Skuce, S. H. McBride, D. M. Wright, M. L. Bermingham, R. Pong-Wong, O. Matika, S. W. J. McDowell, E. J. Glass, and S. C. Bishop. 2014. Genomic prediction for tuberculosis resistance in dairy cattle. PLoS One 9:e96728. https://doi.org/10.1371/journal.pone.0096728.

Tsiamadis, V., G. Banos, N. Panousis, M. Kritsepi-Konstantinou, G. Arsenos, and G. E. Valergakis. 2016a. Genetic parameters of calcium, phosphorus, magnesium, and potassium serum concentrations during the first 8 days after calving in Holstein cows. J. Dairy Sci. 99:5535-5544. https://doi.org/10.3168/jds.2015-10787.

Tsiamadis, V., G. Banos, N. Panousis, M. Kritsepi-Konstantinou, G. Arsenos, and G. E. Valergakis. 2016b. Genetic parameters of subclinical macromineral disorders and major clinical diseases in postparturient Holstein cows. J. Dairy Sci. 99:8901-8914. https://doi .org/10.3168/jds.2015-10789.

Uribe, H. A., B. W. Kennedy, S. W. Martin, and D. F. Kelton. 1995. Genetic parameters for common health disorders of Holstein cows. J. Dairy Sci. 78:421-430. https://doi.org/10.3168/jds.S0022 -0302(95)76651-6.

van der Drift, S. G., K. J. van Hulzen, T. G. Teweldemedhn, R. Jorritsma, M. Nielen, and H. C. Heuven. 2012. Genetic and nongenetic variation in plasma and milk $\beta$-hydroxybutyrate and milk acetone concentrations of early-lactation dairy cows. J. Dairy Sci. 95:6781-6787. https://doi.org/10.3168/jds.2012-5640.

Weigel, K. A., R. S. Pralle, H. Adams, K. Cho, C. Do, and H. M. White. 2017. Prediction of whole-genome risk for selection and management of hyperketonemia in Holstein dairy cattle. J. Anim. Breed. Genet. 134:275-285. https://doi.org/10.1111/jbg.12259.

Whitaker, D. A. 2004. Metabolic profiles. Pages 804-817 in Bovine Medicine: Diseases and Husbandry of Cattle. 2nd ed. Blackwell Science, Oxford, UK.

Wilcox, A. A., W. E. Carroll, R. E. Sterling, H. A. Davis, and A. G. Ware. 1966. Use of the Berthelot reaction in the the automated analysis of serum urea nitrogen. Clin. Chem. 12:151-157.

Yang, J., B. Benyamin, B. P. McEvoy, S. Gordon, A. K. Henders, D. R. Nyholt, P. A. Madden, A. C. Heath, N. G. Martin, G. W. Montgomery, M. E. Goddard, and P. M. Visscher. 2010. Common SNPs explain a large proportion of the heritability for human height. Nat. Genet. 42:565-569. https://doi.org/10.1038/ng.608.

\section{ORCIDS}

T. D. W. Luke ๑ https://orcid.org/0000-0001-5070-2332

T. T. T. Nguyen (1) https://orcid.org/0000-0002-9880-6859

S. Rochfort (๑) https://orcid.org/0000-0001-8442-6081

J. E. Pryce @ https://orcid.org/0000-0002-1397-1282 